\title{
Lung damage created by high tidal volume ventilation in rats with monocrotaline-induced pulmonary hypertension
}

\author{
Masako Kawai ${ }^{1,2}$, Erquan Zhang 1,3, Jane Chanda Kabwe ${ }^{1}$, Amphone Okada', Junko Maruyama 1,2, \\ Hirofumi Sawada ${ }^{1,4}$ and Kazuo Maruyama ${ }^{1 *}$ (i)
}

\begin{abstract}
Background: Rats with chronic hypoxia-induced non-inflammatory pulmonary hypertension (PH) are resistant to ventilator-induced lung injury. We investigated the effect of high tidal volume ventilation in another model of PH, monocrotaline (MCT)-induced $\mathrm{PH}$, which is a type of inflammatory $\mathrm{PH}$.
\end{abstract}

Methods: PH was induced in rats by subcutaneous injection with $60 \mathrm{mg} / \mathrm{kg} \mathrm{MCT}$. Normal control rats, rats at 2 weeks after MCT injection (MCT2), and rats at 3 weeks after MCT injection (MCT3) were ventilated with low tidal volume (LV, $6 \mathrm{~mL} / \mathrm{kg}$ ) or high tidal volume (HV, $35 \mathrm{~mL} / \mathrm{kg}$ ) for $2 \mathrm{~h}$ with room air without positive end-expiratory pressure. Arterial oxygen pressure $\left(\mathrm{PaO}_{2}\right)$ and Evans blue dye (EBD) extravasation were measured. Hypertensive pulmonary vascular remodeling was assessed morphometrically by the percentage of muscularized peripheral pulmonary arteries (\%Muscularization) and the media wall thickness to external diameter ratio, namely percentage medial wall thickness (\%MWT). To assess inflammation, lung IkB protein and cytokine mRNA expression levels were assessed.

Results: Baseline mean pulmonary arterial pressure was significantly higher in MCT rats (normal, $15.4 \pm 0.5 \mathrm{mmHg}$; MCT2, 23.7 \pm 0.9 ; and MCT3, $34.5 \pm 1.5$ ). After 2-h ventilation, $\mathrm{PaO}_{2}$ was significantly lower in the HV groups compared with the LV groups in normal and MCT2 rats, but not in MCT3 rats. Impairment of oxygenation with HV was less in MCT3 rats compared with normal and MCT2 rats. Among the HV groups, MCT3 rats showed significantly lower levels of EBD extravasation than normal and $\mathrm{MCT} 2$ rats. HV significantly downregulated IKB protein expression in normal and MCT3 rats and increased IL-6, MCP-1, CXCL-1 (MIP-1), and IL-10 mRNA levels in MCT3 rats. \%Muscularization, \%MWT, and the expression of lung elastin were significantly higher in MCT3 rats than in normal and MCT2 rats.

Conclusion: We found that HV-associated damage might be reduced in MCT-induced PH rats compared with normal rats. The results of this and earlier studies suggest that hypertensive pulmonary vascular structural changes might be protective against the occurrence of ventilator-induced lung injury, irrespective of the etiology of PH.

Keywords: Ventilator-induced lung injury, Monocrotaline, Mechanical ventilation, Pulmonary hypertension

\footnotetext{
*Correspondence: k-maru@med.mie-u.ac.jp

'Department of Anesthesiology and Critical Care Medicine, Mie

University School of Medicine, 2-174 Edobashi, Tsu, Mie 514-8507, Japan

Full list of author information is available at the end of the article
}

\section{Background}

Mechanical ventilation is used under general anesthesia in patients with and without lung disease and patients with respiratory failure. Injurious ventilation, such as high tidal volume ventilation, might worsen preexisting lung damage or initiate new lung injury in healthy lungs, termed ventilator-induced lung injury (VILI) 
[1-6], which is associated with the release of inflammatory mediators. The induction of an inflammatory response with VILI is evidenced by neutrophil and macrophage infiltration of the lung $[7,8]$ and increases in tumor necrosis factor (TNF) $\alpha$, interleukin (IL)- $1 \alpha$, IL- $1 \beta$, IL-6, and MIP-2 levels in bronchoalveolar lavage fluid [9$11]$ and plasma $[9,10]$ and lung mRNA expression [11].

Pulmonary hypertension (PH) occurs in patients with congenital heart disease with a left-to-right shunt [12-15], chronic obstructive lung disease [16], pulmonary fibrosis [17], and connective tissue disease [18, 19]. Some patients with these conditions may undergo surgery under general anesthesia with mechanical ventilation, and postoperative complications can lead to prolonged mechanical ventilation. In all conditions causing $\mathrm{PH}$ in humans and experimental models of $\mathrm{PH}$ vascular remodeling, there is new muscularization of normally non-muscular peripheral pulmonary arteries, medial wall hypertrophy of muscular arteries, and increased protein expression in vascular connective tissue [12, 15, 20, 21]. Chronic hypoxia-induced $\mathrm{PH}$ [22-27] and monocrotaline (MCT)-induced PH [28-34] in rats are the most commonly used animal models of PH [18, 19, 21, 35], and both models undergo vascular remodeling $[15,20,21]$. In MCT-induced PH, endothelial changes precede the rise of pulmonary artery pressure, which is associated with inflammatory changes, as evidenced by neutrophil and monocyte infiltration and increased inflammatory cytokine expression in the lung, such as IL-1, TNF $\alpha$, and monocyte chemotactic protein (MCP)-1 [18, 2830]. Kornecki et al. showed that vascular remodeling in chronic hypoxia-induced $\mathrm{PH}$ rats protects against the effects of injurious mechanical ventilation in vivo [27]. Thus, this vascular remodeling might have an effect on the development of VILI. Although vascular remodeling is associated with MCT-induced PH, high tidal volume ventilation might exacerbate lung injury given that MCTinduced $\mathrm{PH}$ has an inflammatory component in its etiology $[18,19,28-30]$. Therefore, in the present study, we compared the effects of high tidal volume ventilation in normal rats and MCT-induced $\mathrm{PH}$ rats.

\section{Methods}

\section{Animals}

The Animal Experiments Committee of the Mie University School of Medicine, Mie, Japan approved the study protocol (approval no. 30-13). Seven-week-old male Sprague-Dawley rats (Japan SLC, Inc.) were subcutaneously injected with $60 \mathrm{mg} / \mathrm{kg} \mathrm{MCT} \mathrm{to} \mathrm{induce} \mathrm{PH} \mathrm{[30,} \mathrm{31,}$ 33], and kept for 2 or 3 weeks. Rats at 2 weeks after MCT injection (MCT2) were defined as a mild PH model, whereas those at 3 weeks after MCT injection (MCT3) were defined as a severe $\mathrm{PH}$ model. Age-matched untreated normal rats were used as a normal group. The total number of rats used in this study was 103 . For euthanasia rats were administered $50 \mathrm{mg} / \mathrm{kg}$ pentobarbital sodium (Somuno Pentil injection ${ }^{\circledR}$, Kyoritsu Seiyaku Corporation, Tokyo, Japan) via intraperitoneal injection. After obtaining no consciousness with respiratory depression and no response to the stimulation, which took about 5-10 min and showed deep anesthesia, rats were put under mechanical ventilation through tracheostomy. Then the abdomen was incised and the rats were exsanguinated by aortic incision and heart and lung samples were removed.

\section{Experimental groups}

Eighty-five rats were randomly assigned to one of six groups: (1) rats ventilated with low tidal volume of $6 \mathrm{~mL} /$ $\mathrm{kg}($ normal/LV) $(\mathrm{n}=14)$; (2) rats ventilated with high tidal volume of $35 \mathrm{~mL} / \mathrm{kg}$ (normal/HV) $(\mathrm{n}=22)$; (3) rats ventilated with low tidal volume of $6 \mathrm{~mL} / \mathrm{kg}$ at 2 weeks after a single subcutaneous injection of $60 \mathrm{mg} / \mathrm{kg}$ MCT (MCT2/LV) ( $\mathrm{n}=11)$; (4) rats ventilated with high tidal volume of $35 \mathrm{~mL} / \mathrm{kg}$ at 2 weeks after a single subcutaneous injection of $60 \mathrm{mg} / \mathrm{kg}$ MCT $(\mathrm{MCT} 2 / \mathrm{HV})(\mathrm{n}=15)$; (5) rats ventilated with low tidal volume of $6 \mathrm{~mL} / \mathrm{kg}$ at 3 weeks after a single subcutaneous injection of $60 \mathrm{mg} /$ $\mathrm{kg} \mathrm{MCT}(\mathrm{MCT} 3 / \mathrm{LV})(\mathrm{n}=11)$; and (6) rats ventilated with high tidal volume of $35 \mathrm{~mL} / \mathrm{kg}$ at 3 weeks after a single subcutaneous injection of $60 \mathrm{mg} / \mathrm{kg}$ MCT (MCT3/HV) $(n=12)$. The number of rats used in each experiment are presented in each figure. Rats with mean pulmonary arterial pressure less than $25 \mathrm{mmHg}$ in the MCT3/LV and MCT3/HV group were excluded. Since pulmonary hypertension is a condition defined on condition that the mean pulmonary arterial pressure at rest is $25 \mathrm{mmHg}$ or higher, rats with a mean pulmonary arterial pressure of less than $25 \mathrm{mmHg}$ were excluded in order to examine respiratory management for $\mathrm{MCT} 3 \mathrm{PH}$ rats, ie, severe $\mathrm{PH}$ in the present study.

\section{Catheterization}

Under intraperitoneal pentobarbital sodium (45 mg/ $\mathrm{kg}$ ) anesthesia, a right internal carotid and a pulmonary artery catheter (Silastic tubing, $0.31 \mathrm{~mm}$ inner diameter and $0.64 \mathrm{~mm}$ outer diameter) were inserted by using the closed-chest technique, as described previously [11, 23, 30, 33]. Mean pulmonary arterial pressure (mPAP), and peak inspiratory airway pressure (PIP) at the tracheostomy cannula (SP-110; Natsume, Tokyo, Japan) were recorded with a physiological transducer and amplifier system (AP 620; Nihon Kohden, Tokyo, Japan) [11, 13, $24,25,30,33]$. 


\section{Mechanical ventilation}

The rats were ventilated without positive end-expiratory pressure using an SN-480-7 volume cycle ventilator (Shinano Co., Tokyo, Japan) [11]. All groups of rats were ventilated for $2 \mathrm{~h}$ with room air. The respiratory rate and dead space were adjusted by inserting a tube between the Y-piece of the ventilator circuit and tracheostomy cannula in the high tidal volume groups [11], so that arterial $\mathrm{CO}_{2}$ tension was kept between $40-50 \mathrm{mmHg}$.

\section{Experimental protocol \\ Arterial oxygen pressure}

After 15 min stabilization of ventilation with a tidal volume of $6 \mathrm{~mL} / \mathrm{kg}$, baseline arterial blood gas analysis was performed by a portable blood gas analyzer (iSTAT Analyzer 200; Abbott Point of Care, Inc., Princeton, NJ), which was followed by experimental tidal volume (6 or $35 \mathrm{~mL} / \mathrm{kg}$ ) assignment [11] with continuation of mechanical ventilation for another $2 \mathrm{~h}$. Further arterial blood samples were obtained at $0.5,1.0,1.5$, and $2.0 \mathrm{~h}$ after tidal volume assignment. For the measurement of Evans blue dye (EBD) extravasation, $30 \mathrm{mg} / \mathrm{kg}$ EBD was given intravenously after blood sampling at $0.5 \mathrm{~h}$ after tidal volume assignment. After 2 -h ventilation, tidal volume was returned to $6 \mathrm{~mL} / \mathrm{kg}$ and PIP was measured.

\section{Preparation of lung tissue for determining the percentage of lung water content and EBD extravasation}

At the end of the protocol, lung tissue was obtained to measure lung water content and pulmonary microvascular permeability $[11,33]$. The upper lobe of the right lung was used for the measurement of the percentage of lung water content, (wet lung weight-dried lung weight)/ (wet lung weight) $\times 100$. The rest of the lung was used to determine EBD extravasation into the lung, as an estimate of protein permeability, which was quantitated as described previously [11, 35-37].

\section{Right ventricular hypertrophy}

To estimate right ventricular hypertrophy $(\mathrm{RVH})$, the heart was removed and fixed in buffered neutral formaldehyde solution $[23,33]$. The right ventricle (RV) of the heart was dissected from the left ventricle plus septum $(\mathrm{LV}+\mathrm{S})$ and weighed separately. The heart weight ratio $(\mathrm{RV} /[\mathrm{LV}+\mathrm{S}])$ was calculated to assess $\mathrm{RVH}[23,30,33]$.

\section{Lung samples for western blotting, real-time PCR, and vascular structural assessment}

For western blotting and real-time PCR analyses of the lung, the hilum of the right lung was ligated and the right lung was excised and put into liquid nitrogen. To assess hypertensive pulmonary vascular structural changes, the left lung was injected with a hot barium-gelatin mixture at a pressure of $36 \mathrm{cmH}_{2} \mathrm{O}$ and fixed in $10 \%$ formalin for $72 \mathrm{~h}$, as described previously [23-25, 30, 33]. Lung sections were stained for elastin by the Van Gieson method [23-25, 30, 33].

\section{Morphometry of the pulmonary vasculature}

To assess the magnitude of hypertensive pulmonary vascular remodeling, light microscope (Olympus CX33, Tokyo, Japan) slides were analyzed at $\times 400$, without previous knowledge of the treatment group, which was described previously [23-26, 30, 33]. The acquisition resolution of the microscope image was $1920 \times 1440$ pixels. The percentage of muscularized arteries (\%Muscularization) in peripheral pulmonary arteries with an external diameter of $15-50 \mu \mathrm{m}$ and $51-100 \mu \mathrm{m}$ and the ratio of media wall thickness (distance between the external and internal elastic laminae) to the external diameter in small muscular artery, namely percentage medial wall thickness (\%MWT), were calculated $[24,25,30]$. The number of arteries were 445 arteries per section (166-634 arteries per rat). An average 33 (0-75 per section) small muscular arteries with a diameter of 51-100 $\mu \mathrm{m}$ and an average 16 (2-30 arteries per section) small muscular arteries with a diameter of 101-200 $\mu \mathrm{m}$ were analysed, respectively.

\section{Western blotting for ІкB, high-mobility group box 1 , and elastin}

Western blotting for I $\mathrm{I} B$, high-mobility group box 1 (HMGB-1), and elastin in whole lung tissue was performed as described previously [11, 24, 25]. The following primary antibodies were used: anti-HMGB-1 (1:5,000; \#3935S; Cell Signaling Technology, Danvers, MA); anti-IkB $\alpha$ (1:5,000 dilution; \#4814S; Cell Signaling Technology); anti-elastin (1:5,000 dilution; 15257-1-AP; Proteintech, Rosemont, IL); and anti- $\beta$-actin (1:200,000 dilution; A5441; Sigma-Aldrich, St. Louis, MO). The following secondary antibodies were used: anti-mouse IgGHRP (1:20,000 dilution; NA 931; Amersham, Piscataway, NJ) and anti-rabbit IgG-HRP (1:20,000 dilution; D2313; Santa Cruz Biotechnology, Dallas, TX). The immunoreactive bands were visualized with ECL reagents in AlphaView software 3.3.0 (ProteinSimple, San Jose, CA).

\section{TaqMan real-time PCR}

The TaqMan Gene Expression Assay was used for analysis of IL-6 (Rn01410330), IL-10 (Rn01644839), C-X-C motif chemokine ligand 1 (CXCL-1/KC/MIP-1) (Rn00578225), MCP-1 (Rn00580555), HMGB-1 (Rn02377062), Elastin (Rm01499782) and $\beta$-actin (Rn00667869), as described previously [24]. 


\section{BALF sampling}

In the other sets of normal, MCT2 and MCT3 rats $(\mathrm{n}=5$, respectively), bronchoalveolar lavage (BAL) was performed to show the magnitude of lung inflammation without mechanical ventilation. The rats were anesthetized by the intraperitoneal administration of $50 \mathrm{mg} /$ $\mathrm{kg}$ pentobarbital sodium. The BAL fluid (BALF) was obtained by cannulating the trachea with plastic tube and by infusing the lungs with $7-\mathrm{ml}$ of PBS. The recovered fluid (BALF) was centrifuged (2200 rpm, $10 \mathrm{~min}$ ) using a cytofuge (Medite, Germany), and the cells were stained with May Grunwald Giemsa (Merck, Darmstadt, Germany).

\section{Data analysis}

All values are expressed as the mean \pm standard error. Analysis of variance with repeated measures was used for arterial blood gas, hemodynamic and PIP analysis. EBD extravasation, the percentage of lung water content, right ventricular hypertrophy, cytokine and chemokine mRNA levels, IкB and HMGB-1 protein expressions were performed by two-way analysis of variance. Morphologic parameters and elastin protein expression levels were performed by one-way analysis of variance. When significant variance was found, Fisher's predicted least significant difference test was used to establish which groups were different. $p<0.05$ was considered to be significant.

\section{Results}

\section{Arterial oxygen pressure}

\section{Baseline}

There were no significant differences in baseline arterial oxygen $\left(\mathrm{PaO}_{2}\right)$ between the LV and HV groups in normal, MCT2, and MCT3 rats before the administration of high tidal volume ventilation (Fig. 1).

\section{At $2 h$ after the start of high tidal volume ventilation}

After 2-h ventilation, $\mathrm{PaO}_{2}$ was significantly lower in the HV groups compared with the LV groups in normal and MCT2 rats, but not in MCT3 rats (Fig. 1a). Given that $\mathrm{PaO}_{2}$ increased and peaked at $0.5 \mathrm{~h}$ after the start of high tidal volume ventilation and then declined in the $\mathrm{HV}$ groups, we calculated the percentage decrease of $\mathrm{PaO}_{2}$ at $1,1.5$, and $2 \mathrm{~h}$, taking the value at $0.5 \mathrm{~h}$ as a reference. The percentage decrease of $\mathrm{PaO}_{2}$ in the $\mathrm{HV}$ groups at $2 \mathrm{~h}$ was significantly less in MCT3 rats compared with normal and MCT2 rats (Fig. 1b). These results suggested that the

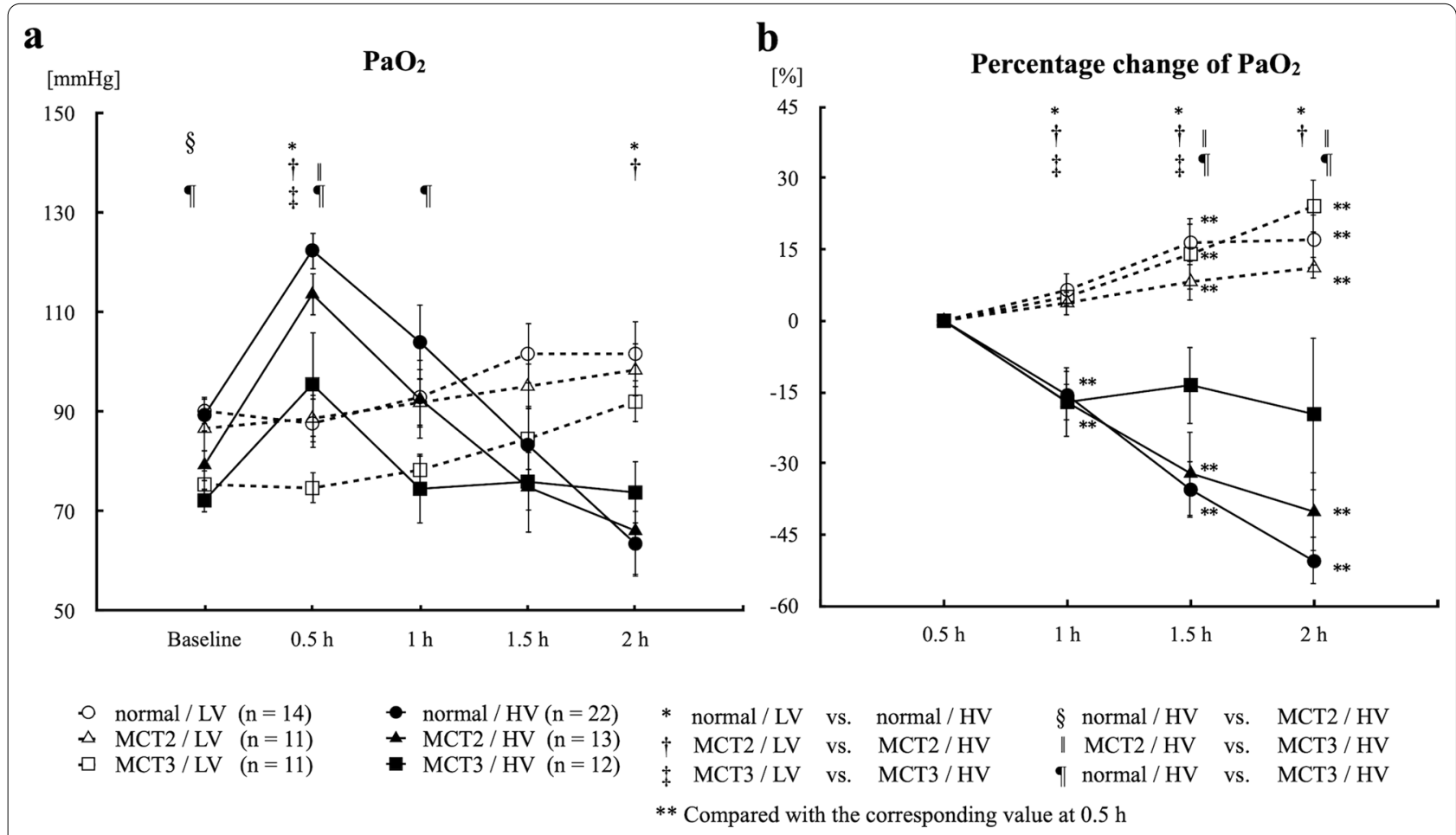

Fig. 1 Arterial oxygen pressure $\left(\mathrm{PaO}_{2}\right)$ and percentage change of $\mathrm{PaO}_{2}$. a $\mathrm{PaO}_{2}$. b Percentage change of $\mathrm{PaO}_{2}$ at $1,1.5$, and $2 \mathrm{~h}$, taking the value at $0.5 \mathrm{~h}$ as a reference. MCT2: rats at 2 weeks after monocrotaline injection; MCT3: rats at 3 weeks after monocrotaline injection; LV: low tidal volume $(6 \mathrm{~mL} / \mathrm{kg}) ; \mathrm{HV}$ : high tidal volume (35 mL/kg); Baseline: immediately after the assignment of experimental tidal volume; $0.5,1,1.5$, and $2 \mathrm{~h}$ : time after the assignment of experimental tidal volume $(6$ or $35 \mathrm{~mL} / \mathrm{kg}$ ). Bars indicate mean \pm standard error. $\mathrm{n}=$ number of rats 
impairment of oxygenation with high tidal volume ventilation was less in MCT3 rats compared with normal and MCT2 rats.

\section{EBD extravasation and the percentage of lung water content}

EBD extravasation, a marker of protein permeability, was significantly increased in all HV groups compared with the corresponding LV groups (Fig. 2a). Among the HV groups, MCT3 rats showed significantly lower EBD extravasation than normal and MCT2 rats. In contrast, among the LV groups, MCT3 rats showed significantly higher EBD extravasation than normal rats (Fig. 2a). The percentage of lung water content was increased in all HV groups compared with the corresponding LV groups in normal, MCT2, and MCT3 rats (Fig. 2b). There were no significant differences in the percentage of lung water content among the HV groups (Fig. 2b).

\section{Mean pulmonary arterial pressure Baseline}

Baseline mPAP was significantly higher in MCT2 and MCT3 rats than in normal rats (mPAP: normal, $15.4 \pm 0.5 \mathrm{mmHg}$; MCT2, $23.7 \pm 0.9 \mathrm{mmHg}$; and MCT3, $34.5 \pm 1.5 \mathrm{mmHg}$ ) (Fig. 3a). This increase in PAP was associated with a significant increase in RVH in MCT3 rats (Fig. 3c), suggesting the development of $\mathrm{PH}$.

\section{Changes of mPAP during mechanical ventilation}

Changes of mPAP were analyzed taking the value at baseline as a reference to detect the effect of $\mathrm{HV}$ ventilation, because this time point was the first time point after the assignment of high tidal volume ventilation. There were no time-dependent changes in MPAP in any of the LV groups. In normal rats, HV ventilation significantly increased mPAP at $0.5,1,1.5$, and $2 \mathrm{~h}$ after the start of mechanical ventilation compared with baseline (Fig. 3a), whereas there were no changes in MCT2 and MCT3 rats in the HV groups.

\section{Peak inspiratory airway pressure}

PIP was not changed in any of the LV groups throughout the course of the experiment. In contrast, PIP was increased in all $\mathrm{HV}$ groups after the assignment of $\mathrm{HV}$ until the end of HV mechanical ventilation. MCT3 rats had significantly higher PIP compared with MCT2 rats (Fig. 3b), suggesting a decrease in lung compliance in MCT3 rats. When the tidal volume in the HV groups was returned to the low volume of $6 \mathrm{~mL} / \mathrm{kg}$ after the end of 2-h ventilation, PIP was reduced, but it was significantly higher than the values prior to $0 \mathrm{~h}$ in all normal, MCT2, and MCT3 rats, suggesting decreased lung compliance after $2 \mathrm{~h}$ in the HV groups.

\section{Vascular structural remodeling}

Representative arteries are shown in Fig. 4, demonstrating new muscularization of peripheral pulmonary arteries (Fig. 4b, c) and hypertrophy of the media in small

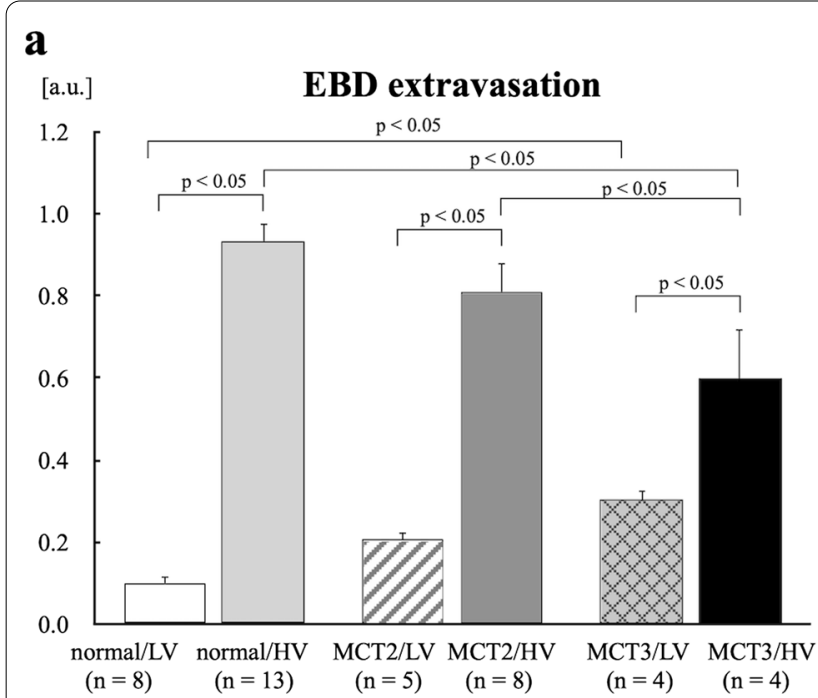

\section{b}

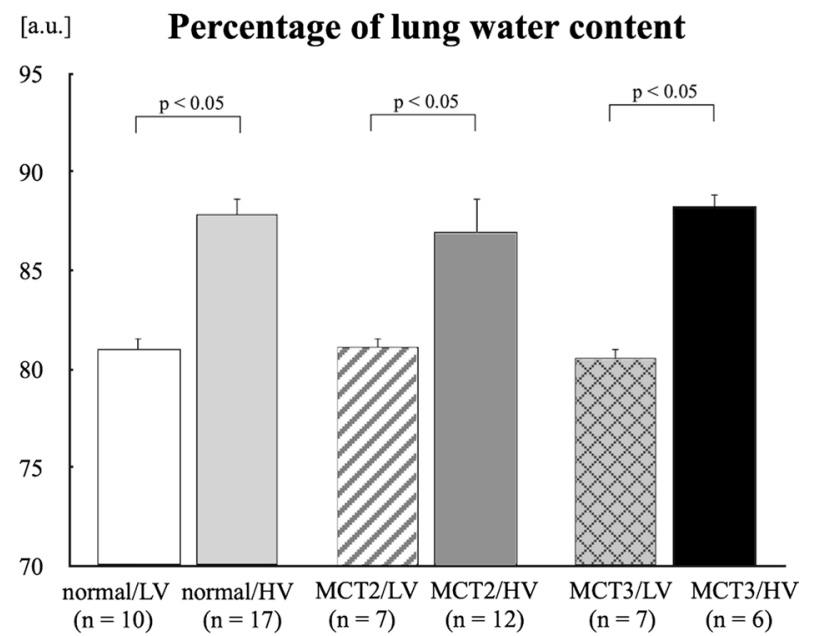

Fig. 2 Evans blue dye (EBD) extravasation and the percentage of lung water content. a EBD extravasation, an estimate of protein permeability. $\mathbf{b}$ The lung dry-to-wet weight ratio, an estimate of lung water content. MCT2: rats at 2 weeks after monocrotaline injection; MCT3: rats at 3 weeks after monocrotaline injection; LV: low tidal volume $(6 \mathrm{~mL} / \mathrm{kg})$; HV: high tidal volume $(35 \mathrm{~mL} / \mathrm{kg})$; a. u.: arbitrary units. Bars indicate mean \pm standard error. $\mathrm{n}=$ number of rats 


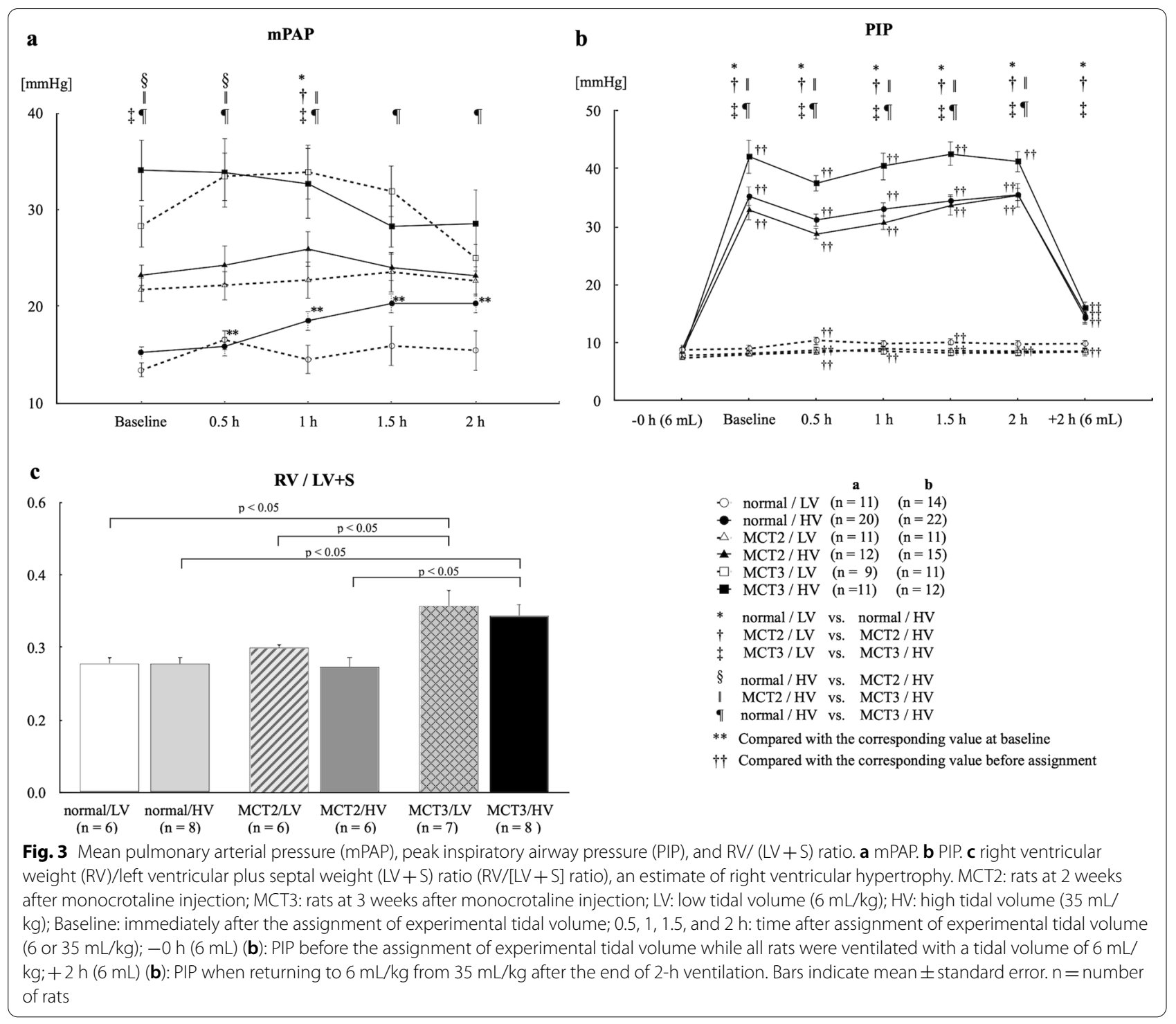

muscular arteries (Fig. 4e, f, h, i). To evaluate hypertensive pulmonary vascular remodeling in the MCT2 and MCT3 groups, \%Muscularization and \%MWT were assessed. The data from the low and high tidal volume groups were combined. To show the inflammatory responses in the lung representative slides of BALF sample are also shown (Fig. 4j, k, l).

\section{Percentage of muscularized peripheral arteries}

MCT increased the percentage of muscularized peripheral arteries in the MCT2 and MCT3 groups compared with the normal group $(p<0.05)$ (Fig. 5a). The MCT3 group had higher \%Muscularization than the MCT2 group in arteries with an external diameter of $51-100 \mu \mathrm{m}$ $(p<0.05)$ (Fig. 5b), suggesting increased muscularization in peripheral pulmonary arteries in the MCT3 group.

\section{Percentage medial wall thickness}

\%MWT was increased in the MCT2 and MCT3 groups compared with the normal group in arteries with an external diameter of $51-100 \mu \mathrm{m}(p<0.05)$ (Fig. 5c). The MCT3 group had higher \%MWT than the MCT2 group in arteries with an external diameter of 51-100 $\mu \mathrm{m}$ and 101-200 $\mu \mathrm{m}(p<0.05)$ (Fig. 5c, d), suggesting increased medial wall thickness in the MCT3 group. 


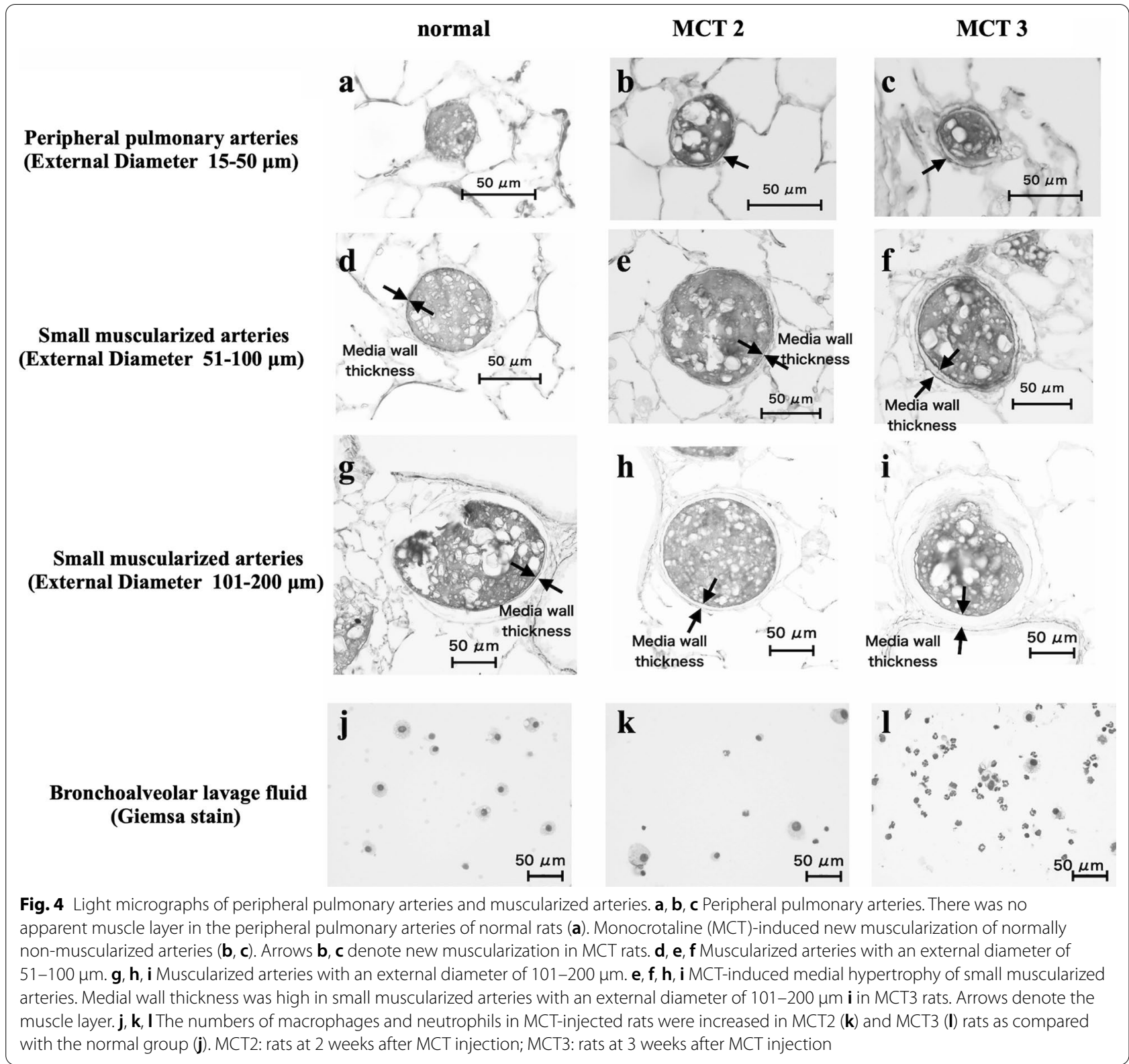

\section{Inflammatory cytokines and chemokines}

To confirm the accentuated inflammatory response in the HV groups compared with the LV groups, we measured cytokine and chemokine mRNA levels in the lungs (Fig. 6). IL-6, MCP-1, CXCL-1 (MIP-1), and IL-10 mRNA levels were similar among the LV groups. High tidal volume ventilation significantly increased IL-6, MCP-1, CXCL-1 (MIP-1), and IL-10 mRNA levels in MCT3 rats and IL-10 and MCP-1 mRNA levels in normal rats compared with low tidal volume ventilation. There was also a trend toward an increase in the levels of IL-6, MCP-1, CXCL-1 (MIP-1), and IL-10 mRNA levels in MCT2 rats and IL-6 mRNA levels in normal rats compared with low tidal volume ventilation, but the values did not reach statistical significance. These trends were consistent with the insignificant downregulation of $I_{\kappa} B$, since the decrease in I $\mathrm{kB}$ shows the inflammatory reaction. $\mathrm{NF} \kappa \mathrm{B}$, which is activated by the decrease in $I_{k} B$, is located in the upstream of inflammatory cytokines.

\section{IKB and HMGB-1}

As our previous study showed a decrease of $\mathrm{I} \kappa \mathrm{B}$ protein expression in lungs from MCT-induced $\mathrm{PH}$ rats [34] and another study showed that HMGB-1 plasma levels are 


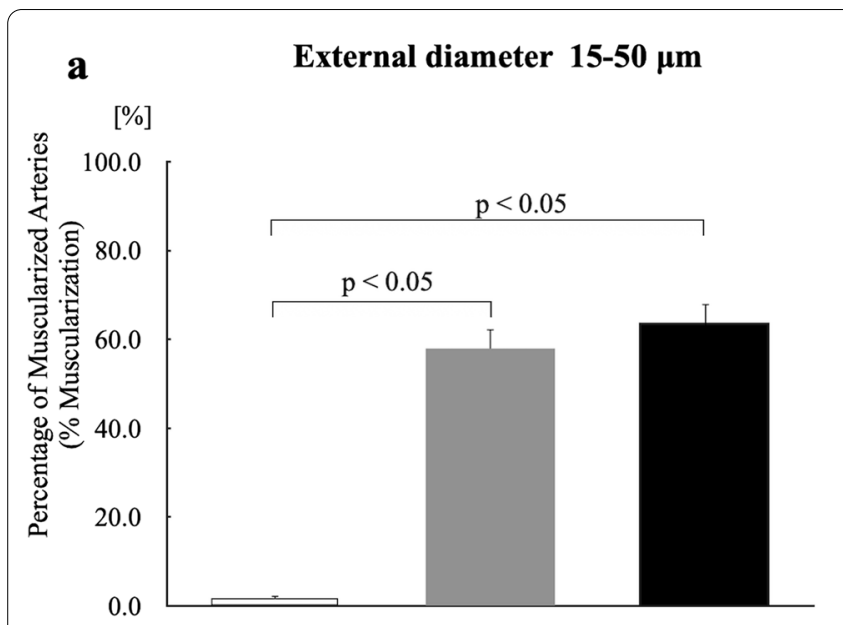

c

External diameter 51-100 $\mu \mathrm{m}$

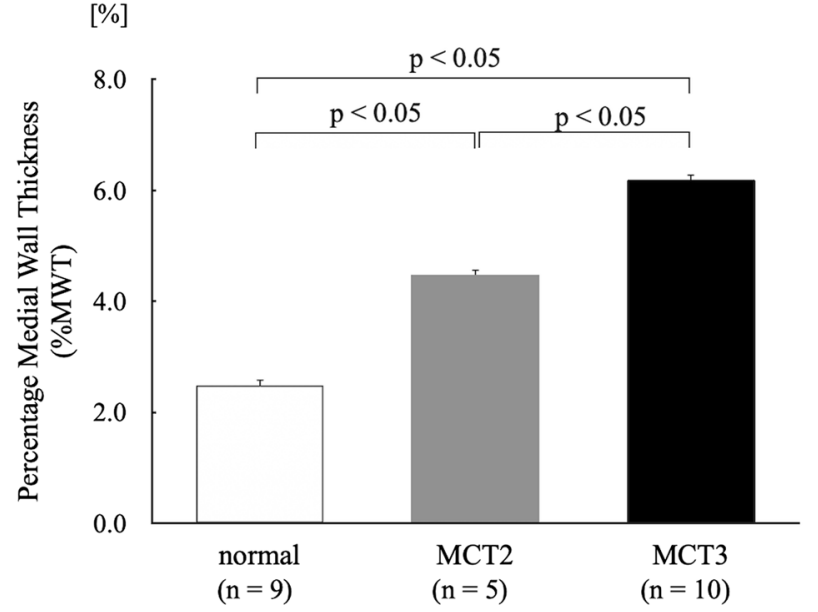

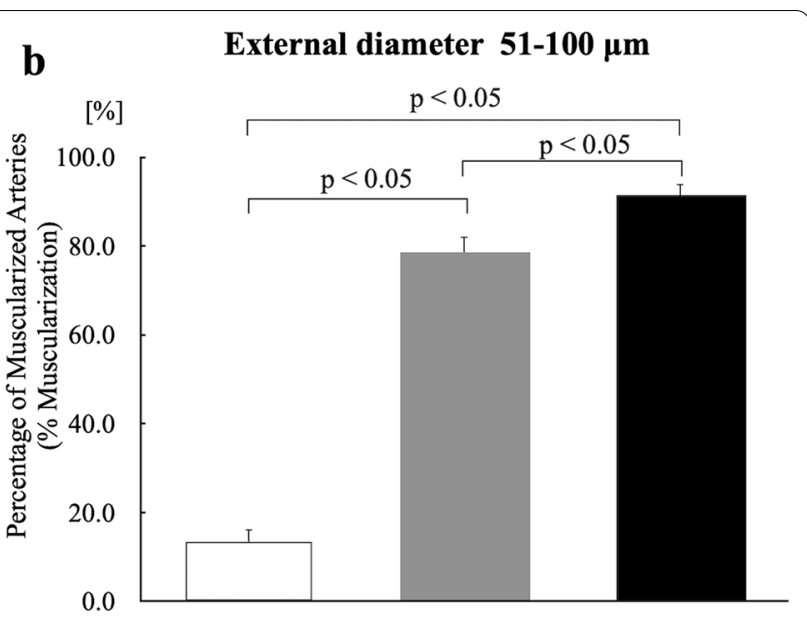

d External diameter 101-200 $\mu \mathrm{m}$

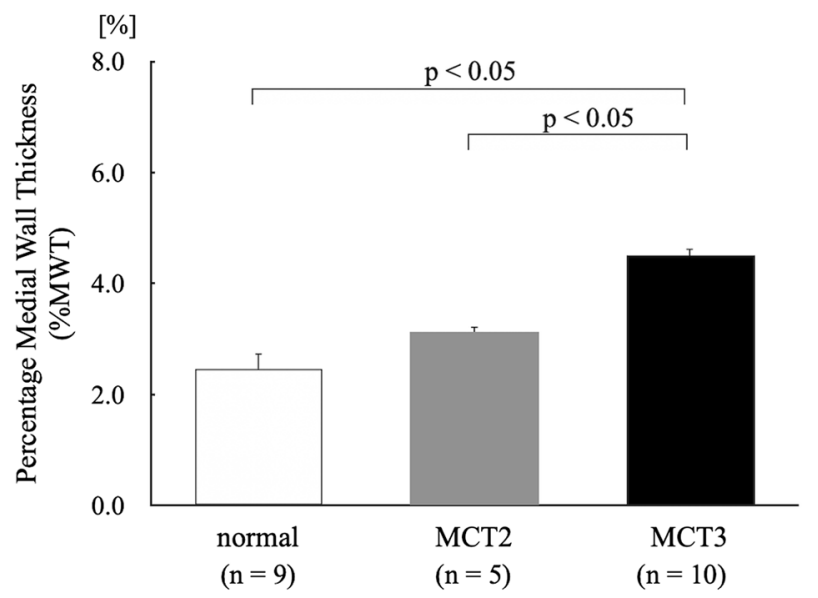

Fig. 5 Vascular structural changes at 2 and 3 weeks after monocrotaline injection. a Percentage of muscularized arteries (\%Muscularization) of peripheral pulmonary arteries with an external diameter of 15-50 $\mu \mathrm{m}$. b \%Muscularization of peripheral pulmonary arteries with an external diameter of 51-100 $\mu \mathrm{m}$. c Percentage medial wall thickness (\%MWT) of muscularized arteries with an external diameter of 51-100 $\mu$ m. $\mathbf{d} \%$ MWT of muscularized arteries with an external diameter of 101-200 $\mu \mathrm{m}$. MCT2: rats at 2 weeks after monocrotaline injection; MCT3: rats at 3 weeks after monocrotaline injection. Bars indicate mean \pm standard error. $n=$ number of rats

elevated in $\mathrm{PH}$ [38], we determined IкB and HMGB-1 expression in lung tissue and the effect of high tidal volume ventilation on their levels. High tidal volume ventilation significantly decreased $\mathrm{I} \kappa \mathrm{B}$ protein expression in normal and MCT3 rats (Fig. 7a) and decreased HMGB-1 protein expression in normal and MCT2 rats but not in MCT3 rats (Fig. 7b). The lung samples of normal group rats (Fig. 7a, b) were obtained from 9- to 10-week-old rats. The values of the percentages of lung water content and EBD extravasation were similar between 9-weekold and 10-week-old normal rats. Therefore, in order to reduce the number of experimental animals, the lung samples of normal groups were selected randomly from the pooled samples of 9-week-old to 10-week-old rats.

\section{Elastin}

To investigate the effect of MCT injection on connective tissue protein, lung elastin protein levels were assessed in normal, MCT2, and MCT3 rats ventilated with low tidal volume. Elastin protein expression was significantly increased in MCT3 rats compared with normal and MCT2 rats (Fig. 7c). Elastin mRNA was increased in MCT2 rats compared to normal rats (Fig. 7d). There was no effect on elastin mRNA levels by high tidal volume ventilation (Fig. 7d). 

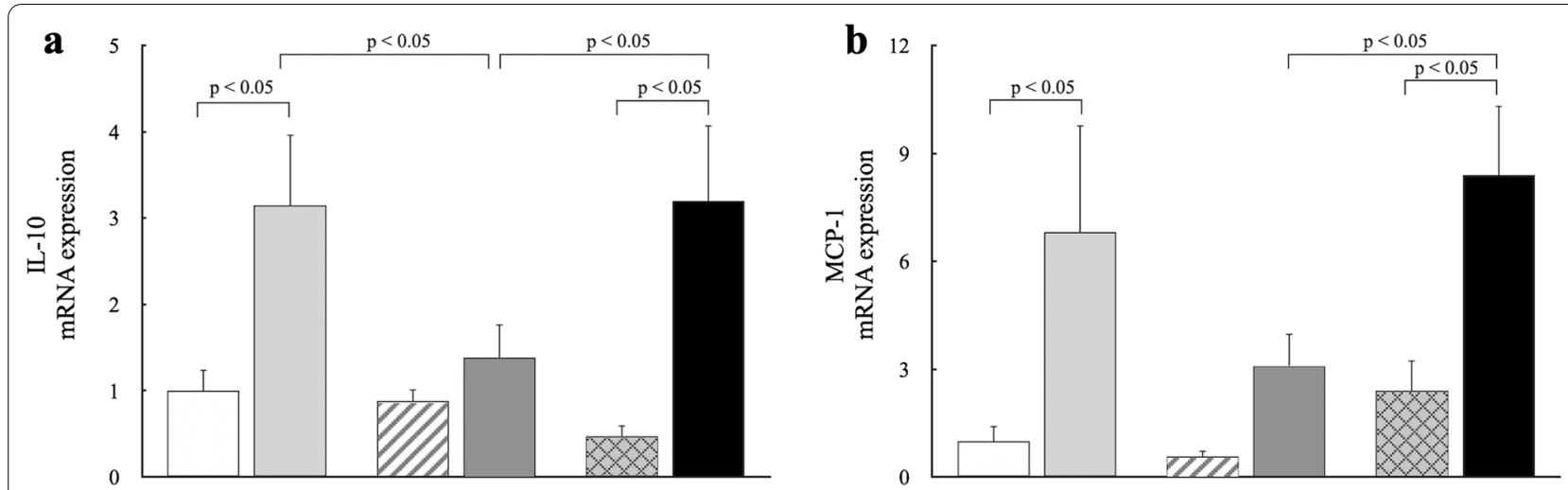

C

d
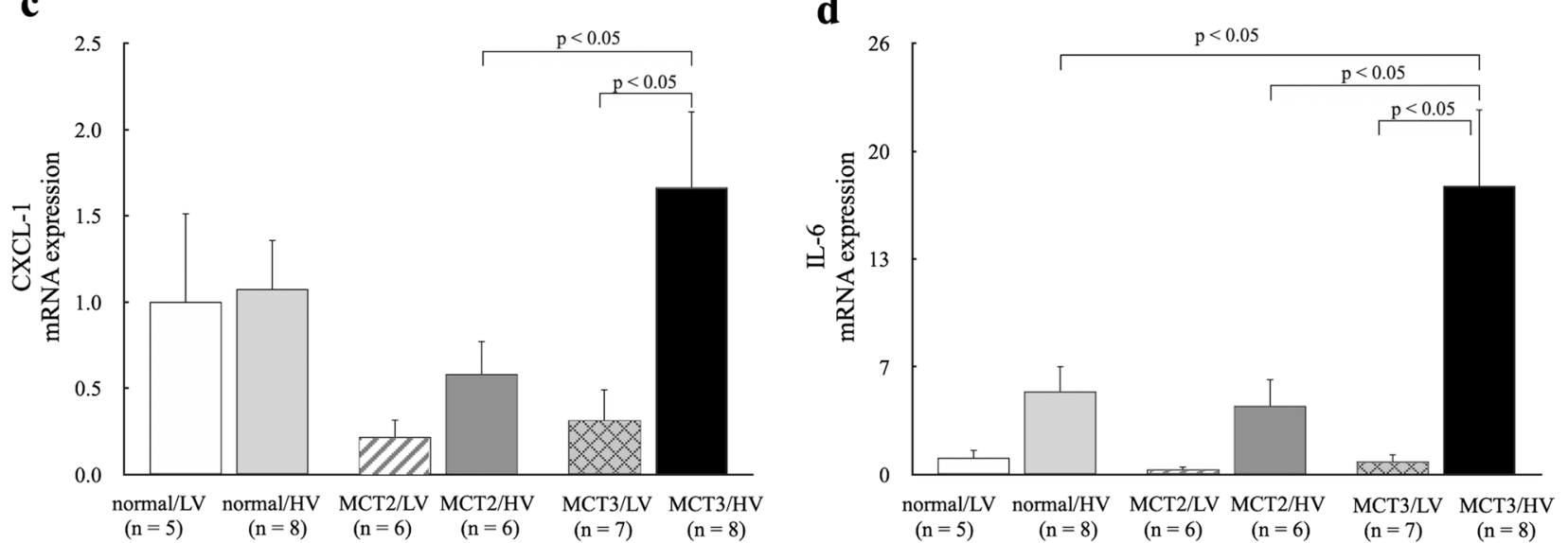

Fig. 6 Real-time PCR analysis of cytokine and chemokine mRNA levels in lung tissue in rats. a Interleukin (IL)-10. b Monocyte chemotactic protein-1 (MCP-1). c Chemokine CXCL-1/KC (MIP-1). d IL-6. MCT2: rats at 2 weeks after monocrotaline injection; MCT3: rats at 3 weeks after monocrotaline injection; LV: low tidal volume $(6 \mathrm{~mL} / \mathrm{kg})$; HV: high tidal volume $(35 \mathrm{~mL} / \mathrm{kg})$. Bars indicate mean \pm standard error. $\mathrm{n}=$ number of rats

\section{Discussion}

MCT caused PH and hypertensive pulmonary vascular remodeling, and MCT3 rats had significantly higher mPAP, more muscularized peripheral pulmonary arteries, and thicker medial walls of small muscularized arteries than MCT2 rats, showing that the magnitude of $\mathrm{PH}$ was severe in MCT3 rats and mild in MCT2 rats. High tidal volume ventilation increased the percentage of lung water content and protein permeability, as measured by EBD extravasation, in normal and PH rats. The deterioration of arterial oxygen tension with high tidal volume ventilation was more attenuated in severe $\mathrm{PH}$ (MCT3) rats compared with normal and mild $\mathrm{PH}$ (MCT2) rats.

The main focus of this study was VILI in PH rats. Since VILI is associated with the release of inflammatory mediators, the presence of inflammation in the lung before mechanical ventilation might exacerbate VILI. So, the inflammatory component of the present MCTinduced $\mathrm{PH}$ model deserve comments, in which reduction of IкB $\alpha$ protein levels were confirmed in the present study. Although the exact mechanism through which
MCT causes $\mathrm{PH}$ is not known, inflammation is considered to have an important role [35]. Neutrophils have been implicated early in the course of MCT injury [15], and mononuclear cells (particularly macrophages) and lymphocytes infiltrate the alveolar wall by 14 days after injection [32], when plasma and bronchoalveolar lavage fluid MCP-1 levels are also elevated [29]. Our previous study showed that MCT treatment significantly reduces I $\mathrm{K} \alpha \alpha$ protein levels in lung tissue, which were restored by treatment with pyrrolidine dithiocarbamate, an NF- $\mathrm{KB}$ inhibitor [34]. NF- $\mathrm{kB}$ is a transcription factor regulating the expression of genes involved in the inflammatory response. A decrease in the protein levels of $I \kappa B \alpha$ has been reported to be associated with the upregulation of NF- $k B$ activity [39].

The severity of lung injury was similar between normal and mild $\mathrm{PH}$ (MCT2) rats with high tidal volume ventilation because there was no difference in the lung wet/dry weight ratio, EBD extravasation, and arterial oxygenation. In contrast, EBD extravasation and arterial oxygenation were less impaired in severe $\mathrm{PH}$ (MCT3) rats compared 


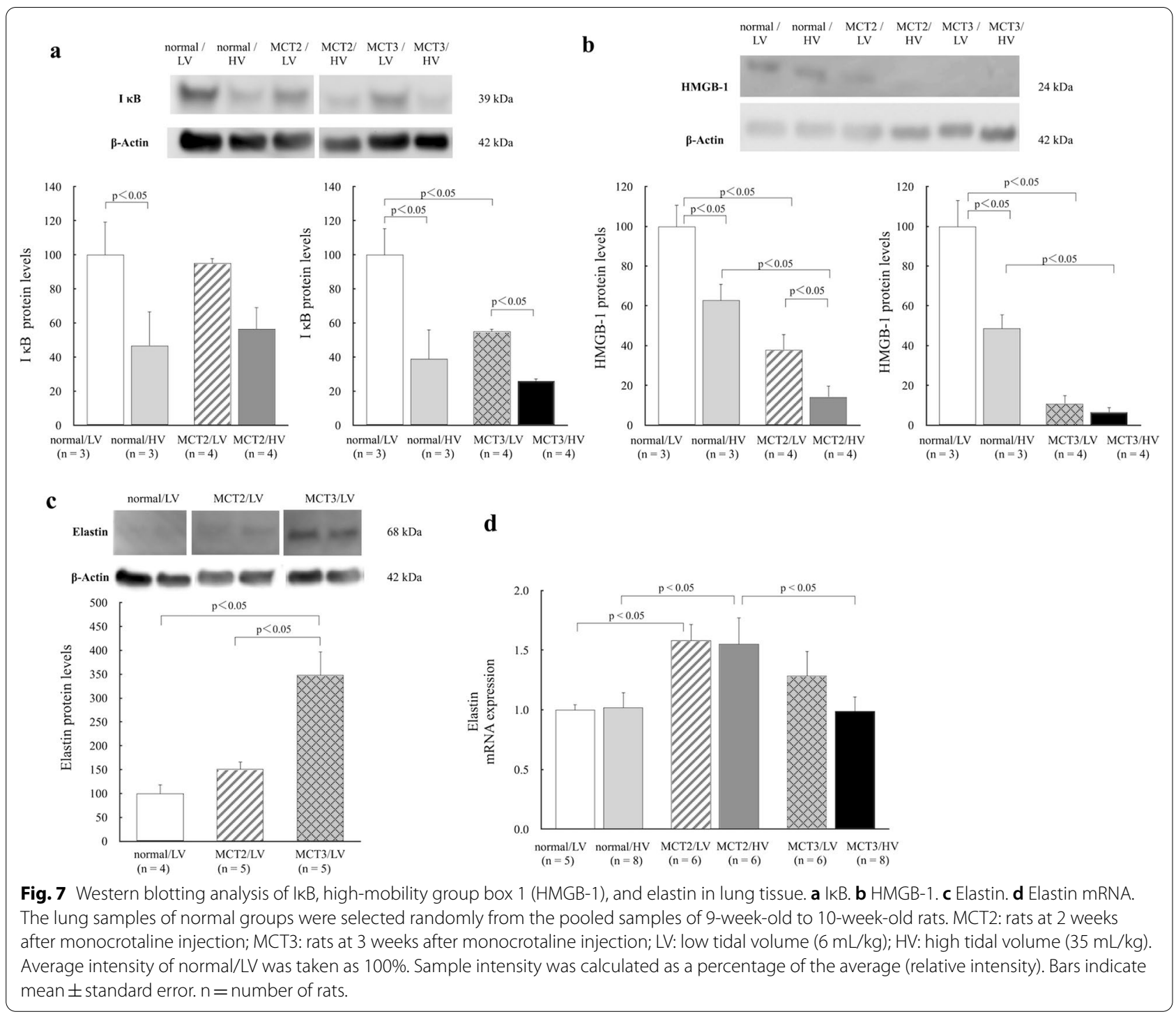

with normal and mild $\mathrm{PH}$ (MCT2) rats, suggesting resistance to high tidal volume ventilation-induced lung injury in this group, which was unexpected. We had anticipated that lung injury caused by high tidal volume ventilation might be more severe in MCT-induced $\mathrm{PH}$ rats compared with normal rats, and that MCT3 rats would have more severe lung injury than MCT2 rats, because MCTinduced $\mathrm{PH}$ is a type of inflammatory $\mathrm{PH}$ and inflammatory cytokines are involved in the development of VILI $[7,8,28-30]$. However, high tidal volume ventilationinduced EBD extravasation was lower in PH lungs than in normal lungs and we could not detect significant differences in arterial oxygenation between high and low tidal volume ventilation in severe $\mathrm{PH}$ rats. It seemed that hypertensive vascular changes may be associated with protection against the development of VILI, regardless of the presence of inflammation.
High tidal volume ventilation tended to increase the expression of proinflammatory cytokines in normal and $\mathrm{PH}$ rats, suggesting an increased inflammatory response with high tidal volume ventilation, which is consistent with earlier reports $[1,2,7-10]$. Under high tidal volume ventilation, severe $\mathrm{PH}$ (MCT3) rats had significantly higher cytokine expression, such as IL-6, IL-10, MCP-1, and CXCL-1, than mild PH (MCT2) rats, showing that the high tidal volume ventilation-induced inflammatory response was accentuated in MCT3 rats compared with MCT2 rats. According to this line of thought, MCT3 rats were expected to have more severe lung damage with high tidal volume ventilation, but this was not the case. Although the inflammatory component was high in MCT3 rats, arterial oxygenation and EBD permeability were less impaired. Because mechanical trauma (volutrauma) and inflammation (biotrauma) additively 
or synergistically cause ventilator-associated lung injury [2], the mechanical trauma component might be reduced in MCT3 rats due to hypertensive vascular remodeling. The increase in transmural and transpulmonary pressure, that is, mechanical forces, during high tidal volume ventilation can cause breaks in the capillary endothelial layer and alveolar epithelium [40], which is mechanical damage. The thick vascular wall in $\mathrm{PH}$ might be less vulnerable to mechanical force compared with normal vasculature. Similar results were observed in another rat model of $\mathrm{PH}$, namely, chronic hypoxia-induced $\mathrm{PH}$, and the authors suggested that the enhanced tensile strength associated with pulmonary vascular remodeling would protect against VILI [27].

Overinflation and the increase in surface forces induced by high tidal volume ventilation both lead to an augmentation of vascular transmural pressure [41], partly leading to the formation of hydrostatic-type edema. Thus, further vascular transmural pressure would be added in the presence of PH under high tidal volume ventilation in normal lung vasculature, thereby inducing lung edema. However, in the PH lung with vascular remodeling, the increase of transmural pressure during high tidal volume ventilation might be less compared with the normal lung owing to the presence of thick-walled vessels with increased stiffness and decreased lung compliance [15, 21], which might reduce the effect of hyperinflation. HV-induced lung edema was comparable among normal, mild $\mathrm{PH}$ and severe $\mathrm{PH}$ rats, which was evaluated by lung the percentage of lung water content (wet lung weight - dried lung weight) $/$ (wet lung weight $) \times 100$ ) in the present study (Fig. 2b). This method was probably insensitive to detect the increased pulmonary permeability than EBD extravasation, since EBD extravasation during $\mathrm{HV}$ ventilation was less in mild and severe $\mathrm{PH}$ rats compared to normal rats (Fig. 2a). EBD extravasation is more sensitive for detecting the increase in protein permeability in the lung than dry/wet weight ratios in the early phase of VILI [11].

HMGB-1 is normally present as a nuclear protein and is passively released from damaged cells [41]. The reduction of HMGB-1 expression in lung tissue from rats with high tidal volume ventilation, consistent with a previous study [11], might be due to the increased release of HMGB-1 protein into the circulation [42, 43], which might reflect cell damage. Because high tidal volume ventilation caused a significant decrease of HMGB-1 expression in MCT2 rats, but not in MCT3 rats, this might suggest that the magnitude of cell damage due to high tidal volume ventilation might be less in MCT3 rats.

Given that elevated vascular wall stress in $\mathrm{PH}$ increases the production and accumulation of elastin [44], we determined the expression of elastin in lung tissue and showed that MCT3 rats had significantly higher lung elastin levels than normal and MCT2 rats. Regardless of the etiology, hypertensive pulmonary vascular remodeling includes new muscularization of normally nonmuscularized peripheral pulmonary arteries, medial wall hypertrophy of muscularized arteries, and increased vascular connective tissue protein levels such as collagen and elastin [20, 22]. These changes increase vascular stiffness. Arterial stiffness can be increased by an increase in the expression of rigid wall materials such as collagen, elastin, fibronectin, and proteoglycans $[15,45]$, which was evidenced by the higher levels of lung elastin observed in MCT3 rats by western blotting in the present study. Smooth muscle cell hypertrophy and hyperplasia are associated with the increased production of collagen because these cells produce connective tissues such as collagen and elastin $[15,22,31]$. In thick-walled pulmonary arteries, a process of degradation and increased synthesis of connective tissue protein in the subendothelium and media occurs [31]. The width of the elastic lamina and volume of collagen are increased in MCT-injected rats compared with non-treated rats [31]. In the present study, hypertensive pulmonary vascular changes were clearly more accentuated in severe PH (MCT3) rats compared with mild PH rats (MCT2), which possibly resulted in the increased vascular stiffness. This increased stiffness might lead to protection from the increased pressure outside of the vasculature associated with lung overinflation. In normal vasculature, lung inflation flattens the peripheral pulmonary vasculature, raising the tension of the vasculature [46], which might be reduced in hypertensive vasculature because of increased stiffness. PIP after the start of high tidal volume ventilation was higher in $\mathrm{PH}$ rats than in normal rats, suggesting decreased lung compliance in $\mathrm{PH}$ rats, where severe $\mathrm{PH}$ (MCT3) rats had less lung compliance than mild PH (MCT2) rats. An increase in connective tissue protein levels in the $\mathrm{PH}$ lung might decrease compliance [21].

\section{Limitations}

The first limitation of this study is that it was observational and not mechanistic. Although observational, this study suggested a relationship between hypertensive pulmonary vascular remodeling and the occurrence of VILI. Most of the previous studies have used control rats and/or rats treated with $\mathrm{HCl}$ [4], lipopolysaccharides [5], alpha-naphtylthiourea [3], and $100 \% \mathrm{O}_{2}$ [11], which are acute models without hypertensive vascular remodeling. Second, the MCT model does not completely recapitulate human pulmonary arterial hypertension. However, the most commonly used animal PH models are the chronic hypoxia-induced PH model and MCT-PH model; the former as a model of $\mathrm{PH}$ in patients residing at high altitude and those with chronic obstructive pulmonary disease, 
and the latter as a model of pulmonary arterial hypertension $[18,19]$ and inflammation-related $\mathrm{PH}$. Because an earlier study demonstrated that vascular remodeling is protective against the development of VILI in ventilated chronic hypoxia-induced $\mathrm{PH}$ rats with high tidal volume [27], the present results in the MCT model were similar to those in hypoxia-induced PH. Thus, taking these results into consideration, we could say that vascular remodeling might be protective against the effect of injurious mechanical ventilation, regardless of the etiology of PH. Third, the magnitude of protection might be subtle given that we could not detect a significant decrease in the percentage of lung water content. However, lung permeability and arterial oxygenation were less deteriorated in severe $\mathrm{PH}$ rats. The percentage of lung water content might be less sensitive than EBD extravasation [11]. Fourth, although hypertensive vasculature might be protective against mechanical force to the lung itself, the systemic effect of inflammatory cytokines from the $\mathrm{PH}$ lung might cause remote organ failure, such as the kidney and liver because VILI is associated with or causes multiple organ dysfunction [1]. Further investigations are necessary to determine the presence of the dysfunction of remote organs other than the lung in $\mathrm{PH}$ rats. It is of great interest whether use of $\mathrm{HV}$ improves or worsens the prognosis of $\mathrm{PH}$ since the expression of genes involved in the inflammatory response in the lung was changed after HV. Thus, mean pulmonary arterial pressure and pulmonary vascular remodeling 1-2 weeks after HV would deserve investigation. Whether or not HV worsens the prognosis of $\mathrm{PH}$ might be judged by examining the survival rate until 5 weeks with time course.

\section{Conclusion}

In summary, the results reported here and those from a previous study [27] showed that hypertensive pulmonary vascular structural changes might protect against the occurrence of VILI, which might attenuate the magnitude of lung injury.
Additional file 1. The original gels in Fig. 7a, 7b, and 7c.

\section{Acknowledgements}

The authors thank Drs. H. Oshita and N. Tsuboya for technical assistance. We are also grateful to Ms. N. Hiramatsu for secretarial assistance.

\section{Authors' contributions}

MK and EZ contributed equally to this work, collecting and analyzing the data, and drafting the manuscript. JK, AO, and JM made substantial contributions to data collection and reviewing the manuscript. HS participated in the design of the study. KM conceived the study, participated in its design and coordination, and helped to draft the manuscript. All authors read and approved the final manuscript.

\section{Funding}

This work was financially supported by Grants-In-Aid for Scientific Research (18K16464 to MK, 16K10933 to EZ, 18K08192 to JM, 17K10140 to HS, and

$17 \mathrm{~K} 11075$ to KM) from the Japanese Ministry of Education, Culture, Sports, Science and Technology. It was used for expenses related to animal experiments (rat purchase costs, breeding costs, analysis reagents). In addition, the English composition was made using the funds of 18K16464 to MK.

\section{Availability of data and materials}

All original data will be made available upon from the first author (m.kawai@ suzuka-u.ac.jp) reasonable request.

\section{Declarations}

\section{Ethics approval and consent to participate}

All of the animal procedures had been approved by the Animal Experiments Committee of the Mie University School of Medicine (approval no. 30-13) and also carried out in compliance with the ARRIVE guidelines.

\section{Consent for publication}

Not applicable.

\section{Competing interests}

The authors declare that they have no competing interests.

\section{Author details}

${ }^{1}$ Department of Anesthesiology and Critical Care Medicine, Mie University School of Medicine, 2-174 Edobashi, Tsu, Mie 514-8507, Japan. ${ }^{2}$ Faculty of Medical Engineering, Suzuka University of Medical Science, 1001-1 Kishioka, Suzuka, Mie 510-0293, Japan. ${ }^{3}$ Neonatology, Fuzhou Children's Hospital of Fujian Medical University, 145-817 Middle Road, Gulou, Fuzhou 350005, Fujian, China. ${ }^{4}$ Department of Pediatrics, Mie University School of Medicine, 2-174 Edobashi, Tsu, Mie 514-8507, Japan.

Received: 2 September 2021 Accepted: 17 February 2022

Published online: 05 March 2022

\section{References}

1. Curley GF, Laffey JG, Zhang H, Slutsky AS. Biotrauma and ventilatorinduced lung injury: clinical implications. Chest. 2016;150(5):1109-17.

2. Tremblay LN, Slutsky AS. Ventilator-induced lung injury: from the bench to the bedside. Intensive Care Med. 2006;32(1):24-33.

3. Slutsky AS, Ranieri VM. Ventilator-induced lung injury. N Engl J Med. 2014;370(10):980.

4. Dreyfuss D, Soler P, Saumon G. Mechanical ventilation-induced pulmonary edema. Interaction with previous lung alterations. Am J Respir Crit Care Med. 1995;151(5):1568-75.

5. Chiumello D, Pristine G, Slutsky AS. Mechanical ventilation affects local and systemic cytokines in an animal model of acute respiratory distress syndrome. Am J Respir Crit Care Med. 1999;160(1):109-16.

6. Haitsma JJ, Uhlig S, Göggel R, Verbrugge SJ, Lachmann U, Lachmann B. Ventilator-induced lung injury leads to loss of alveolar and systemic
The online version contains supplementary material available at https://doi. org/10.1186/s12890-022-01867-6. 
compartmentalization of tumor necrosis factor-alpha. Intensive Care Med. 2000;26(10):1515-22.

7. Imanaka H, Shimaoka M, Matsuura N, Nishimura M, Ohta N, Kiyono H. Ventilator-induced lung injury is associated with neutrophil infiltration, macrophage activation, and TGF-beta 1 mRNA upregulation in rat lungs. Anesth Analg. 2001;92(2):428-36.

8. Tremblay L, Valenza F, Ribeiro SP, Li J, Slutsky AS. Injurious ventilatory strategies increase cytokines and c-fos m-RNA expression in an isolated rat lung model. J Clin Invest. 1997;99(5):944-52.

9. D’Angelo E, Koutsoukou A, Della Valle P, Gentile G, Pecchiari M. Cytokine release, small airway injury, and parenchymal damage during mechanica ventilation in normal open-chest rats. J Appl Physiol. 2008;104(1):41-9.

10. Boost KA, Hoegl S, Dolfen A, Czerwonka H, Scheiermann P, Zwissler B, Hofstetter C. Inhaled levosimendan reduces mortality and release of proinflammatory mediators in a rat model of experimental ventilatorinduced lung injury. Crit Care Med. 2008;36(6):1873-9.

11. Iwashita Y, Zhang E, Maruyama J, Yokochi A, Yamada Y, Sawada H, Mitani Y, Imai H, Suzuki K, Maruyama K. Thrombomodulin protects against lung damage created by high level of oxygen with large tidal volume mechanical ventilation in rats. J Intensive Care. 2014:2(1):57.

12. Rabinovitch M, Keane JF, Norwood WI, Castaneda AR, Reid L. Vascular structure in lung tissue obtained at biopsy correlated with pulmonary hemodynamic findings after repair of congenital heart defects. Circulation. 1984;69:655-67.

13. Maruyama K, Maruyama J, Utsunomiya H, Furuhashi K, Kurobuchi M, Katayama Y, Yada I, Muneyuki M. Effect of nicardipine on pulmonary hypertension after repair of congenital heart defects in early postoperative period. J Anesth. 1993;7:95-101.

14. Shimpo H, Mitani Y, Tanaka J, Mizumoto T, Onoda K, Tani K, Yuasa H, Yada I, Maruyama K. Inhaled low-dose nitric oxide for postoperative care in patients with congenital heart defects. Artif Organs. 1997;21:10-3.

15. Rabinovitch M. Problems of pulmonary hypertension in children with congenital cardiac defects. Chest. 1988;93(3 Suppl):119S-126S.

16. Yoshida M, Taguchi O, Gabazza EC, Kobayashi T, Yamakami T, Kobayashi H, Maruyama K, Shima T. Combined inhalation of nitric oxide and oxygen in chronic obstructive pulmonary disease. Am J Respir Crit Care Med. 1997;155(2):526-9.

17. Maruyama K, Kobayasi H, Taguchi O, Chikusa H, Muneyuki M. Higher doses of inhaled nitric oxide might be less effective in improving oxygenation in a patient with interstitial pulmonary fibrosis. Anesth Analg. 1995:81:210-1.

18. Dorfmüller P, Perros F, Balabanian K, Humbert M. Inflammation in pulmonary arterial hypertension. Eur Respir J. 2003;22(2):358-63.

19. Price LC, Wort SJ, Perros F, Dorfmüller P, Huertas A, Montani D, CohenKaminsky S, Humbert M. Inflammation in pulmonary arterial hypertension. Chest. 2012;141(1):210-21.

20. Rabinovitch M. Molecular pathogenesis of pulmonary arterial hypertension. J Clin Invest. 2008;1 18:2372-9.

21. Stenmark KR, Orton EC, Reeves JT, Voelkel NF, Crouch EC, Parks WC, Mecham RP. Vascular remodeling in neonatal pulmonary hypertension. Role of the smooth muscle cell. Chest. 1988;93(3 Suppl):127S-133S.

22. Crouch EC, Parks WC, Rosenbaum JL, Chang D, Whitehouse L, Wu LJ, Stenmark KR, Orton EC, Mecham RP. Regulation of collagen production by medial smooth muscle cells in hypoxic pulmonary hypertension. Am Rev Respir Dis. 1989;140(4):1045-51.

23. Maruyama K, Ye CL, Woo M, Venkatacharya $H$, Lines LD, Silver MM, Rabinovitch M. Chronic hypoxic pulmonary hypertension in rats and increased elastolytic activity. Am J Physiol. 1991;261(6 Pt 2):H1716-26.

24. Zhang E, Maruyama J, Yokochi A, Mitani Y, Sawada H, Nishikawa M, Ma N, Maruyama K. Sarpogrelate hydrochloride, a serotonin 5HT2A receptor antagonist, ameliorates the development of chronic hypoxic pulmonary hypertension in rats. J Anesth. 2015;29(5):715-23.

25. Zhang E, Jiang B, Yokochi A, Maruyama J, Mitani Y, Ma N, Maruyama K. Effect of all-trans-retinoic acid on the development of chronic hypoxiainduced pulmonary hypertension. Circ J. 2010;74(8):1696-703.

26. Jiang BH, Maruyama J, Yokochi A, Iwasaki M, Amano H, Mitani Y, Maruyama K. Prolonged nitric oxide inhalation fails to regress hypoxic vascular remodeling in rat lung. Chest. 2004;125(6):2247-52.

27. Kornecki A, Engelberts D, McNamara P, Jankov RP, McCaul C, Ackerley C, Post M, Kavanagh BP. Vascular remodeling protects against ventilator-induced lung injury in the in vivo rat. Anesthesiology. 2008;108(6):1047-54

28. Voelkel NF, Tuder RM, Bridges J, Arend WP. Interleukin-1 receptor antagonist treatment reduces pulmonary hypertension generated in rats by monocrotaline. Am J Respir Cell Mol Biol. 1994;11(6):664-75.

29. Kimura H, Kasahara Y, Kurosu K, Sugito K, Takiguchi Y, Terai M, Mikata A, Natsume M, Mukaida N, Matsushima K, Kuriyama T. Alleviation of monocrotaline-induced pulmonary hypertension by antibodies to monocyte chemotactic and activating factor/monocyte chemoattractant protein-1. Lab Invest. 1998;78(5):571-81.

30. Yamada Y, Maruyama J, Zhang E, Okada A, Yokochi A, Sawada H, Mitani Y, Hayashi T, Suzuki K, Maruyama K. Effect of thrombomodulin on the development of monocrotaline-induced pulmonary hypertension. J Anesth. 2014;28(1):26-33.

31. Ye CL, Rabinovitch M. Inhibition of elastolysis by SC-37698 reduces development and progression of monocrotaline pulmonary hypertension. Am J Physiol. 1991;261(4 Pt 2):H1255-67.

32. Meyrick B, Gamble W, Reid L. Development of Crotalaria pulmonary hypertension: hemodynamic and structural study. Am J Physiol. 1980:239(5):H692-702.

33. Maruyama J, Maruyama K, Mitani Y, Kitabatake M, Yamauchi T, Miyasaka K. Continuous low-dose NO inhalation does not prevent monocrotalineinduced pulmonary hypertension in rats. Am J Physiol. 1997;272(1 Pt 2):H517-24.

34. Sawada H, Mitani Y, Maruyama J, Jiang BH, Ikeyama Y, Dida FA, Yamamoto H, Imanaka-Yoshida K, Shimpo H, Mizoguchi A, Maruyama K, Komada Y. A nuclear factor-kappaB inhibitor pyrrolidine dithiocarbamate ameliorates pulmonary hypertension in rats. Chest. 2007;132:1265-74.

35. Stenmark KR, Meyrick B, Galie N, Mooi WJ, McMurtry IF. Animal models of pulmonary arterial hypertension: the hope for etiological discovery and pharmacological cure. Am J Physiol Lung Cell Mol Physiol. 2009;297(6):L1013-32.

36. Kumagai $M$, Horiguchi $T$, Nishikawa T, Masaki Y, Tobe $Y$. Intravenous dexmedetomidine decreases lung permeability induced by intracranial hypertension in rats. Anesth Analg. 2008;107:643-7.

37. Teke Z, Sacar M, Yenisey C, Atalay AO, Bicakci T, Erdem E. Activated protein $C$ attenuates intestinal reperfusion-induced acute lung injury: an experimental study in a rat model. Am J Surg. 2008;195(6):861-73.

38. Dai M, Xiao R, Cai L, Ge T, Zhu L, Hu Q. HMGB1 is mechanistically essential in the development of experimental pulmonary hypertension. Am J Physiol Cell Physiol. 2019;316:C175-85.

39. Beg AA, Finco TS, Nantermet PV, Baldwin AS Jr. Tumor necrosis factor and interleukin-1 lead to phosphorylation and loss of I kappa B alpha: a mechanism for NF-kappa B activation. Mol Cell Biol. 1993;13:3301-10.

40. West JB, Tsukimoto K, Mathieu-Costello O, Prediletto R. Stress failure in pulmonary capillaries. J Appl Physiol. 1991;70(4):1731-42.

41. Dreyfuss D, Basset G, Soler P, Saumon G. Intermittent positive-pressure hyperventilation with high inflation pressures produces pulmonary microvascular injury in rats. Am Rev Respir Dis. 1985;132(4):880-4.

42. Andersson U, Tracey KJ. HMGB1 is a therapeutic target for sterile inflammation and infection. Annu Rev Immunol. 2011;29:139-62.

43. Nakamura K, Hatano E, Miyagawa-Hayashino A, Okuno M, Koyama Y, Narita M, Seo S, Taura K, Uemoto S. Soluble thrombomodulin attenuates sinusoidal obstruction syndrome in rat through suppression of high mobility group box 1. Liver Int. 2014;34:1473-87.

44. Todorovich-Hunter L, Johnson DJ, Ranger P, Keeley FW, Rabinovitch M. Altered elastin and collagen synthesis associated with progressive pulmonary hypertension induced by monocrotaline. A biochemical and ultrastructural study. Lab Investig. 1988;58(2):184-95.

45. Zhang Y, Lacolley P, Protogerou AD, Safar ME. Arterial stiffness in hypertension and function of large arteries. Am J Hypertens. 2020;33(4):291-6. https://doi.org/10.1093/ajh/hpz193.

46. Fu Z, Costello ML, Tsukimoto K, Prediletto R, Elliott AR, Mathieu-Costello $\mathrm{O}$, West JB. High lung volume increases stress failure in pulmonary capillaries. J Appl Physiol. 1992;73(1):123-33.

\section{Publisher's Note}

Springer Nature remains neutral with regard to jurisdictional claims in published maps and institutional affiliations. 